\title{
Adaptation to climate change in small island settlements
}

\author{
David C. Major ${ }^{a, *}$, Paul Blaschke ${ }^{b}$, Vivien Gornitz ${ }^{c}$, Emily Hosek ${ }^{\mathrm{d}}$, Martin Lehmann ${ }^{\mathrm{e}}$, \\ James Lewis ${ }^{\mathrm{f}}$, Heiko Loehr ${ }^{\mathrm{f}}$, Graham A. Major-Ex ${ }^{\mathrm{g}}$, Maibritt Pedersen Zari ${ }^{\mathrm{h}}$, \\ María José Vásquez Vargas ${ }^{i}$, Evan Watterson ${ }^{f}$, Anja Wejs ${ }^{j}$ \\ ${ }^{\text {a } I n d e p e n d e n t ~ S c h o l a r, ~ U S A ~}$ \\ ${ }^{\mathrm{b}}$ Blaschke \& Rutherford Environmental Consultants, New Zealand \\ c Columbia University, USA \\ ${ }^{\mathrm{d}}$ Partnership on Sustainability and Low Carbon Transport, USA \\ e Aalborg University, Denmark \\ ${ }^{\mathrm{f}}$ Bluecoast Consulting Engineers, Australia \\ ${ }^{\mathrm{g}}$ Business Consultant, USA \\ ${ }^{\mathrm{h}}$ Victoria University of Wellington, New Zealand

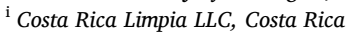 \\ ${ }^{j}$ Central Denmark Region, Denmark
}

\section{A R T I C L E I N F O}

\section{Keywords:}

Climate policy

Small coastal towns

Climate adaptation

Coastal management

\begin{abstract}
A B S T R A C T
Adaptation to climate change in small island settlements poses unique issues of access, cost, governance and cultural, historical, and ecological preservation. There is a need therefore to focus research efforts on these small coastal settlements in order to assist and support their communities to develop and implement adaptation. This article is an initial attempt to evaluate and categorise these issues for island settlements, based on case studies and general perspectives on adaptation. Six island settlement case studies are used from around the world: Cocos Islands (Australian territory); Shishmaref, USA; Broad Channel, USA; Sams $\varnothing$, Denmark; Ciutadella de Menorca, Spain; and Port Vila, Vanuatu. This article describes and assesses impacts, adaptations, and capacity within each of the six case studies, and outlines the relationship of the Sustainable Development Goals system to small coastal settlements in general.
\end{abstract}

\section{Introduction}

The impact of climate change on island and other coastal settlements is likely to be severe, as hazards including sea level rise, storm surges, flooding, erosion, and salt-water intrusion are increasingly impacting coastal assets (Neumann et al., 2015; Major and Juhola, 2016; Vitousek et al., 2017). To reduce the impact of climate change at the coast, island and other coastal settlements need to adapt to increase resilience. Adaptation is underway in many cities worldwide, e.g. New York City (New York City, Office of the Mayor, 2013); however coastal towns and small cities, including those on islands, are not able to adapt as easily (Major and Juhola, 2016). These towns and small cities are disadvantaged as they are not able to access expertise, local climate data, and financial resources as easily as larger cities. There is a need therefore to focus research efforts on small coastal settlements, including those on islands, in order to assist and support their communities to develop and implement adaptation.

This article, on island settlements, forms part of a special issue on adaptation in coastal towns and small cities of less than 100,000 population (see the Introduction to this special issue, Lehmann et al., 2021a). The purpose of this article is to provide some of the initial groundwork to help make adaptations to climate change more effective and efficient in small coastal settlements on islands. It is hoped that this will help to reduce uncertainties for both settlement populations and aid agencies. The article uses six detailed case studies of small island coastal cities and towns as the basis of the analysis, together with other

\footnotetext{
* Corresponding author. 200 West 20th Street \#1103, New York, NY, 10011 USA.

E-mail addresses: david.c.major@gmail.com (D.C. Major), paul@blaschkerutherford.co.nz (P. Blaschke), vmg1@columbia.edu (V. Gornitz), emhosek@gmail.com

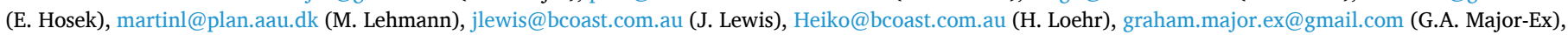

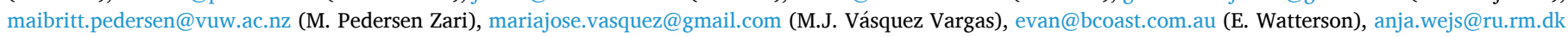
(A. Wejs).
} 
information on islands and adaptation as appropriate. The case studies used are listed in Table 1, and their locations are shown on the world map, Fig. 1. The supplemental on-line materials for each case are referenced in the case study summaries in Section 5 . As will be seen in the supplemental materials, the assessments of the cases depend on reports and other planning documents, some articles, and in some cases discussions with local planners and other stakeholders.

\subsection{Island towns and cities}

An island (other terms are used for very small islands, e.g. islets) is defined as a land mass surrounded by water. Islands can range from very small to very large. In this work, we are concerned with islands entirely surrounded by ocean, although it is clear that there are some estuarine and river islands that face climate impacts such as sea level rise and storm surge typical of islands in the ocean. Worldwide there is a very large number of islands. The choice of scale is of course key to estimating numbers of islands. To take one size class, for example, Depraetere and Dahl (2018, p. 29; see this source for other size classes), estimate a world total of $8,800,000$ "islets" with areas ranging from $10^{-4} \mathrm{~km}^{2}$ to $10 \mathrm{~km}^{2}$. Many settlements on islands, such as those included in this paper, are located on the coasts for reasons of access to subsistence or market economic activity, transport, and recreation, or simply because an island is so small that any settlement is essentially coastal.

There is a considerable body of literature on islands. For example, there is a recent volume, (Baldacchino, ed., 2018) of more than 450 pages that covers many aspects of islands; and there are also specialized journals, such as Island Studies Journal (ISJ), a scholarly journal dedicated to the interdisciplinary study of islands (https://www.islandst udies.ca/). However, compared to the number of small island settlements worldwide, which is unknown but must be large, much more must be done to study and encourage adaptation to climate change on them; that is the focus of this paper. From the standpoint of adaptation, there are two principal elements regarding island settlements that, on the whole, distinguish these from mainland settlements. First, their relative isolation may separate them from access to resources of all kinds, including resources to help recovery from natural disasters, and second, managed retreat or re-location (on the same island) are for many such settlements not realistic possibilities. For both of these reasons, island settlements can face greater challenges in planning and implementing adaptation measures than mainland settlements.

\subsection{Island settlement types}

The choice of which island coastal settlements should be included in this analysis is to some extent a practical matter rather than one of strict definition, i.e., not just the fact of a settlement being on an island in the ocean, but the conditions under which the settlement is on the island

Table 1

Case studies used for the chapter analysis.

\begin{tabular}{|c|c|c|c|}
\hline Settlement & Population & Location & Comments \\
\hline Cocos Islands & $\begin{array}{l}\text { Home Island } \\
\text { 400; West } \\
\text { Island } 140\end{array}$ & $\begin{array}{l}\text { Indian Ocean (Australian } \\
\text { Territory) }\end{array}$ & $\begin{array}{l}\text { Home mainly } \\
\text { Malay; West } \\
\text { mainly Australian }\end{array}$ \\
\hline Shishmaref & 600 & $\begin{array}{l}\text { Barrier island, Western } \\
\text { Alaska, USA }\end{array}$ & $\begin{array}{l}\text { Inupiat } \\
\text { Community }\end{array}$ \\
\hline $\begin{array}{l}\text { Broad } \\
\text { Channel }\end{array}$ & 2400 & Jamaica Bay NYC USA & $\begin{array}{l}\text { Isolated but } \\
\text { connected }\end{array}$ \\
\hline Sams $\varnothing$ & 3720 & $\begin{array}{l}\text { Within in the Kattegat } 15 \\
\text { km east of Jutland, } \\
\text { Peninsula, Denmark }\end{array}$ & $\begin{array}{l}\text { Renewable energy } \\
\text { community }\end{array}$ \\
\hline $\begin{array}{l}\text { Ciutadella de } \\
\text { Menorca }\end{array}$ & 28,600 & $\begin{array}{l}\text { Mediterranean Balearic } \\
\text { Island, Spain }\end{array}$ & Touristic city \\
\hline Port Vila & 75,000 & Vanuatu, Pacific Ocean & $\begin{array}{l}\text { On Efate Island. } \\
\text { Capital of } \\
\text { Vanuatu. }\end{array}$ \\
\hline
\end{tabular}

and the size of the island. For example, a wealthy coastal village on Long Island, NY is effectively a mainland settlement for analytic purposes. Such a village is located on a large, rich, technologically advanced island connected via bridges and tunnels to the Bronx on the New York State mainland, and to Manhattan and Staten Island and from them to the New Jersey mainland. Moreover, the westernmost parts of the island are the boroughs of Queens and Brooklyn in New York City. On the other hand, Broad Channel (described below), a very small inhabited island within Queens, New York City that is an inholding in the Jamaica Bay Wildlife Refuge, part of the U.S. Gateway National Recreation Area, has some characteristics of isolated islands. To take another example, Sri Lanka is an island but is large enough that its coastal settlements would not necessarily have the characteristics of island coastal communities. The area of Sri Lanka $\left(65,610 \mathrm{~km}^{2}\right)$ is about equal to the area of the US State of West Virginia $\left(62,259 \mathrm{~km}^{2}\right)$ or the European country of Lithuania $\left(65,300 \mathrm{~km}^{2}\right)$; its coastal settlements would more properly be the province of the articles to follow on mainland settlements than of this article.

\subsection{Further considerations}

While most current work on adaptation relates to existing settlements, there are other elements of islands that are very important and should be considered in adaptation planning. These include, first, island biodiversity, going back to Darwin's observations (Darwin, 1872, ch. 13), including the famous case of the Galápagos Islands, and brought to the fore in the 20th century by MacArthur and Wilson's seminal volume on island biogeography (1967). Second, there are irreplaceable historic and cultural features such as the famous statues of Easter Island, which also, along with settlements, deserve careful consideration in adaptation planning; Fig. 2 shows some of these near the shore.

\section{Impacts, adaptations, and adaptive capacity}

\subsection{Climate change impacts on coastal island settlements}

These include, as is true also for mainland coastal settlements: sea level rise; storm surge; wave damage; frequency and intensity of rainfall and flooding; frequency and duration of droughts; heat waves; and other extreme events such as wind, snow, and lightning. The main immediate impacts on island coastal settlements are sea level rise and storm surge; other possibly important impacts for some settlements include ocean warming and circulation effects on fisheries; ocean acidification and impacts on coral reefs; and the impacts of temperature and salinization on fresh water sources. Impacts will vary depending on many social, physical, economic, and other considerations noted in the paper on typology in this special issue.

\subsection{Main types of adaptation}

These include "hard defences" infrastructure (such as a flood wall, levees, breakwaters, etc.): "soft" defence measures (raising and revegetating dunes, beach nourishment, coastal wetlands restoration and preservation); management (emergency evacuation planning and execution, ecosystem-based adaptations); and policy (land use zoning, building code strengthening, agreements to coordinate with other settlements or higher levels of government). The principal methods for coastal island settlement protection have been barriers, seawalls, levees, retreat and evacuation. Softer defence measures are increasingly being evaluated. For the long term, permanent removal and resettlement ("managed retreat") may be appropriate in many cases.

\subsection{Adaptive capacity}

Island settlements, because of their isolation, face challenges in developing strong adaptive capacity. The most important elements of 


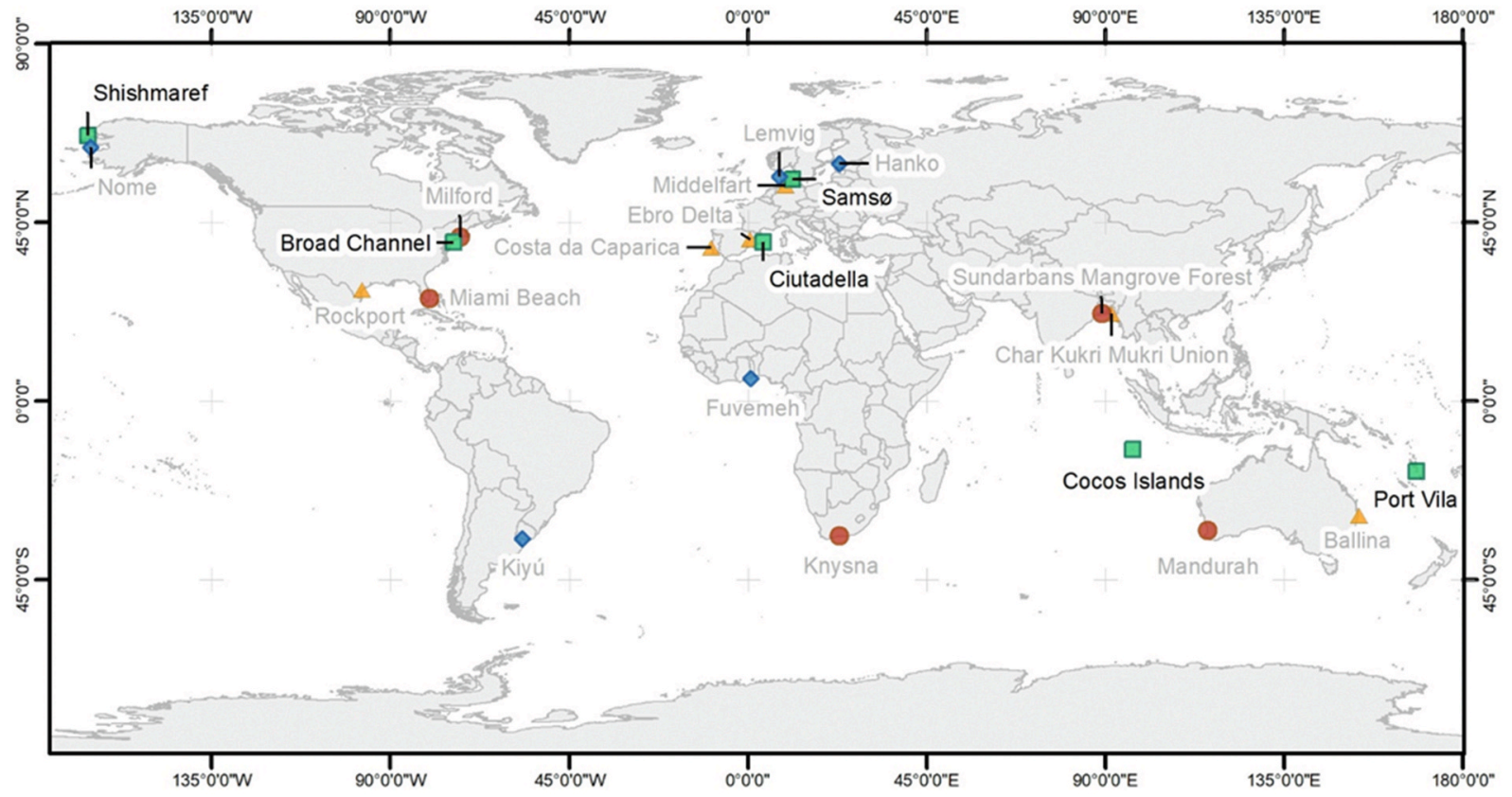

Islands

Broad Channel, USA

Ciutdella, Spain

Cocos Islands. Australia

Port Villa, Vanuatu

Sams $\varnothing$, Denmark

Shismaref, USA
$<10,000$

Fuvemeh, Ghana

Hanko, Finland

Kiyú, Uruguay

Lemvig, Denmark

Nome, Alaksa, USA
10,000 to 50,000

Ballina, Australia

Char Kukri Mukri Union, Bangladesh

Costa da Caparica, Portugal

Ebro Delta, Spain

Middelfart, Denmark

Rockport, USA
$50,000-100,000$

Knysna, South Africa

Miami Beach, USA

Milford, USA

Sundarbans Mangrove Forest, Bangladesh Mandurah, Australia

Fig. 1. Location of the six island settlements considered in this paper, and the settlements considered in the other articles in this Special Issue. An overview set of conclusions from all of the articles in the Special Issue will be found in the final article.

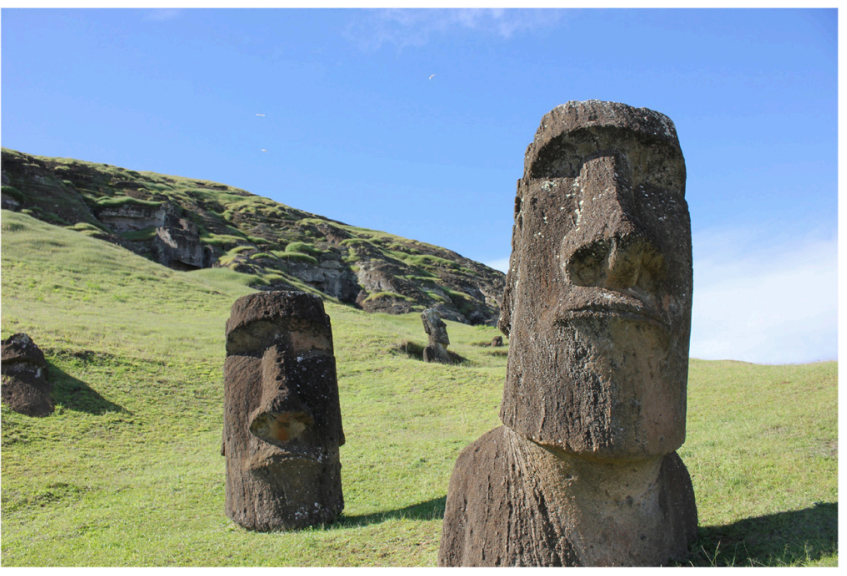

Fig. 2. The Rapa Nui National Park on Easter Island is a UNESCO World Heritage site; the monuments are in danger from rising seas and storm surge (Rapa Nui is the Polynesian name of Easter Island). Photo courtesy of Dale F. Simpson Jr.

adaptive capacity include economic resources, technology, information, skills (such as engineering), existing infrastructure (that can be adapted), institutions, and equity (Major and Juhola, 2021; Smit and Pilifosova, 2001).

It can be seen immediately that many of these elements are weak or missing in many small coastal island settlements. Moreover, there are special barriers to adaptation for island coastal settlements: shortage of engineers and other skilled personnel; high transportation costs for materials and labour, and in general all aspects of adaptation that require overcoming barriers of isolation, such as regular interaction with higher levels of government and the availability of information.

\section{Small island coastal cities and towns: case studies}

The case study descriptions are arranged in ascending order of population. References for statements in the island descriptions are found in the supplemental materials in each case.

\subsection{Cocos Islands}

The Cocos (Keeling) Islands (CKI) are a remote territory of Australia located in the Indian Ocean around $2750 \mathrm{~km}$ northwest of Perth, Western Australia. Only two of the 26 low lying coral sand islands, Home Island and West Island, are inhabited. The community on Home Island is made up of around 400 people who are predominately Cocos Malay. West Island is home to a community of around 140 residents who are predominately from mainland Australia. The islands currently face erosion, tropical cyclones, inundation from Indian Ocean swells and saltwater intrusion. Home Island has flooding during King tides. As a result, the impact of rising sea levels presents a significant climate change adaptation challenge. While the territory is administered by the Australian federal government much of the coastal management is undertaken by the local shire council. Responding to coastal hazards is currently a difficult task for the local shire council due to limited financial and physical resources and a lack of coastal management strategy, but federally funded resources mean that the local shire is better equipped to facilitate adaptation than many other island communities. However, the ad-hoc response to current hazards and coastal 
management in general would benefit from greater coastal process understanding. This is a conclusion that might hold for many small island communities. (See Cocos Islands supplemental material.)

\subsection{Shishmaref}

Shishmaref, Alaska is a small Inupiat (Native American) coastal city (it is a city according to Alaskan law; see supplemental materials) of 600 residents located north of the Bering Strait on a barrier island. The city has received extensive attention and funding for current impacts and climate adaptation to date. The case of Shishmaref has many elements of interest to adaptation planning. Shishmaref is representative of other small island coastal towns in several respects, and quite different in at least one significant way. First, the community is located on a barrier island, like many other small coastal towns. Second, relocation, as is true for many relatively well-developed towns like Shishmaref, will be very expensive and take a matter of years, so that careful scheduling of temporary and permanent adaptations will be important. A third way in which the case of Shishmaref is representative is that the town has contributed very little to climate change, yet it is bearing the consequences. Fourth, the city is a settlement of minority peoples, which is not uncommon for island communities. The principal way in which the case of Shishmaref is different from those of many small island coastal communities worldwide is in the extent to which very substantial resources have already been devoted, and may increasingly be devoted, to its protection and adaptation. But ultimately, the community is likely to have to be relocated to higher ground on the mainland. There are few developing nations that could have careful studies supported by state and national governments and millions of dollars of assistance for protection and possible relocation for a community of some 600 people. (See Shishmaref supplemental material.)

\subsection{Broad Channel}

Broad Channel, population $\sim 2,400$, is a small, closely-knit residential island enclave in Jamaica Bay, a lagoon shielded from the Atlantic Ocean by the Rockaway spit, within the large, densely-populated city of New York. It is an inholding within the Jamaica Bay Wildlife Refuge, which itself is part of the U.S. Gateway National Recreation Area, National Park Service. It is unusual in being an inhabited island directly connected to the larger city via road and subway. Yet it provides several interesting insights into island challenges. It was a hard-hit neighborhood during Hurricane Sandy in 2012, and moreover some streets on the island already flood regularly during heavy rain events and spring high tides. Broad Channel is fortunate to be located in New York City, which is a leading city in undertaking coastal adaptation measures in response to climate change. However, the hazards that it will face in the future present the question of whether or when resilience measures will be inadequate to preserve the island as a residential area, especially at high cost for a small population. Despite its location in a prosperous city, its risks are exacerbated by future sea level rise, and are common to other small island coastal communities throughout the world. (See Broad Channel supplemental material.)

\subsection{Sams $\phi$}

Sams $\emptyset$ is an island with several small settlements located east of the Jutland Peninsula in the sea area called the Kattegat that lies between Denmark and Sweden. The island has 3720 (2018) inhabitants and an area of $114 \mathrm{~km}^{2}$. It is a wealthy community with good transportation links by ferry to the mainland. The island has a long history, including serving as a meeting place during the Viking Age. Today the main industries are agriculture and tourism. In 1997 the island won a government competition to become a renewable energy community, replacing its dependence on oil and coal, both imported from the mainland. The island now produces $100 \%$ of its electricity from wind and heating and some transportation from solar panels and biomass. It is working toward replacing all non-renewable sources and has become something of a model community in that respect. It faces serious flooding (as in 2013) from heavy rains and surge in the Kattegat, which traps water on the island; these problems are expected to increase with more severe storms under climate change. Sams $\varnothing$ is looking to improve water retention through pond relocation, installation of new sewers, and other measures to deal both with current problems and future climate change problems without hard infrastructure. (See Sams $\emptyset$ supplemental material.)

\subsection{Ciutadella de Menorca}

Ciutadella is a municipality of Menorca (also referred to as Minorca), one of the Balearic Islands, located in the Mediterranean Sea, belonging to Spain. Ciutadella is one of the two principal cities of Menorca. It is especially vulnerable to climate change, with a coastline surrounding more than half of the city. The estimated 2017 population of the city is 28,838 , which almost triples in summer due to tourism. Ciutadella faces multiple hazards both current and future, including maritime storms, flooding, winds and sea level rise. The city has multiple layers of governance: in addition to international agreements, there is direct governance from the EU, Spain, the Balearics; Menorca; and the local city council. A review and analysis of adaptation policies at these levels as they have played out in Ciutadella indicates that little effective adaptation has occurred. The local government's capacity in addressing climate change is limited, and those actions taken mainly focus on improving the ability to cope with current climate variability and do not take into account projected climate impacts. A conclusion is that significantly more effort is required to improve local capacity for adaptation. It is essential to emphasize the importance of local governments for the implementation of climate actions as well as the need for efficient links between national and local governments. (See Ciutadella de Menorca supplemental material.)

\subsection{Port Vila}

Vanuatu is a small culturally diverse archipelago in the south-west Pacific Ocean. It consists of over 80 islands set in a large oceanic zone of more than $660,000 \mathrm{~km}^{2}$ with a total landmass of only $12,200 \mathrm{~km}^{2}$. Vanuatu is one of the most at-risk countries in the world related to natural disasters based on its exposure to earthquakes, storms, floods, droughts and sea level rise. The coastal city of Port Vila is the capital and largest city of Vanuatu. Its greater metro area population is approximately 75,000, which is more than a quarter of Vanuatu's total population. High population growth rates exist, mostly due to internal migration. Significant externally funded efforts have been made to develop various climate change adaptation strategies and implementation projects. This includes notable ecosystem-based adaptation (EbA) work through the Secretariat of the Pacific Regional Environment Programme's Pacific Ecosystem-Based Adaptation to Climate Change (PEBACC) programme. For each of the proposed EbA projects risks to implementation, the contribution of outputs to improved adaptation, and the magnitudes of project effects were investigated. One lesson learned from this case study is that while substantial adaptation planning can be done in developing island nation contexts, actual implementation of such strategies can be difficult, and is the true test of the success of such planning initiatives. (See Port Vila supplemental material.)

\section{Observations and conclusions}

These are the principal observations and conclusions from the case studies, together with suggestions intended to make progress toward the goal of better climate change adaptation in small island coastal communities. 


\subsection{Impacts and vulnerabilities}

Impacts and vulnerabilities are very clear in each of the case studies. These include multiple impacts from sea level rise, storm surge, wind, and salinization and the consequent economic and other vulnerabilities. In the case of the Cocos Islands, impacts even include swells in the Indian Ocean. While the case studies are not of course a random sample-indeed they are written about precisely because of their multiple impacts and vulnerabilities-they appear to represent a very large fraction of island coastal settlements by demonstrating the widespread and serious existence of impacts and vulnerabilities. In some cases these can include the potential loss of cultural cohesion, as can happen when communities are forced to relocate.

\subsection{Climate change adaptations and planning}

This is a subject on which significant progress is needed. While there are cases like that of Sams $\varnothing$ where green planning rather than hard infrastructure (as in Shishmaref) is well advanced, and sophisticated planning attempts such as those on Port Vila, most island settlements need much more advanced planning and assessment measures to avoid ad hoc responses (Cocos Islands). Such planning and assessment is very expensive on a case-by-case basis, as can be seen in the case of Shishmaref. Studies that group island coastal settlements by type are needed, so that adaptation planning guidelines, such as those developed by the New York City Panel on Climate Change (Major and O'Grady, 2010) can be adjusted to assist effective planning in many more settlements at lower costs. Among other things, there needs to be a better understanding of the need to integrate planning for current vulnerabilities with longer-range planning for climate change, as is pointed out in the study of Ciutadella.

\subsection{Adaptive capacity}

Adaptive capacity varies widely in the case studies, but overall appears to be lacking in island coastal settlements. A sophisticated island such as Sams $\varnothing$ is as well placed for adaptation as mainland Danish communities of similar size. Broad Channel has little capacity of its own, but sits within a large city that is a leader in adaptation (although this may well not result in the protection of this highly vulnerable island in the long run). Ciutadella has been hampered by multiple layers of government, and communities such as the Cocos Islands and Shishmaref are largely lacking in adaptive capacity, with the gaps filled by government at higher levels.

Adaptive capacity can be augmented or substituted for in several ways, such as: the availability of adaptation cost estimates from similar communities; better climate and other information through technology; and more regular interactions between island communities in general with appropriate government and international agencies and groups, such as the opportunities afforded by the Sustainable Development Goals system, explained in the next section. It should be noted that information exchange between small settlements and higher-level groups and agencies can work both ways.

For example, local knowledge may be the best source of historic flood heights while population data may come from regional agencies. Some scientific information, such as local mass density changes in ocean height, must come from national or world scientific sources, as well as some other information, such as isostatic rebound, that adds to or subtracts from global sea level estimates.

\subsection{Environmental justice}

Most small island coastal communities have contributed very little to climate change, yet as the case studies show, they are among the first to bear major consequences. This raises the issue of moral obligation on the part of large emitters including large cities and has significant implications in terms of environmental justice. These implications are even stronger when the small island coastal communities impacted by climate change are minority communities.

\subsection{Linking small settlements to the Sustainable Development Goals}

An important element of continuing work on climate change adaptation for small coastal cities and towns is linking to larger adaptation programs of states and international organizations. This can especially help to cope with the disadvantages stemming from the isolation of island coastal settlements. One significant aspect of this is the set of Sustainable Development Goals (SGDs) adopted by the United Nations (United Nations, 2015, 2016). The 17 Sustainable Development Goals, or SDGs, cover topics from poverty alleviation and ending hunger to gender equality, climate change, and sustainable economic growth. The SDGs include a monitoring framework of 169 targets (quantified sub-components of a goal that will contribute to its achievement), and a set of 232 indicators, which are precise metrics used to assess if a target is being met (United Nations, n.d., https://unstats.un.org/sdgs/indi cators/database/). As small coastal cities and towns begin plans to adapt to the risks of climate change, the 2030 Agenda and its 17 Sustainable Development Goals can provide a useful framework to develop, monitor, and communicate adaptation plans (Major et al., 2018). Among the most significant SDGs for small coastal settlements are: SDG 1 , "End poverty in all its forms everywhere"; 11 , "Make cities and human settlements inclusive, safe, resilient and sustainable" and SDG 13, "Take urgent action to combat climate change and its impacts".

Beyond helping small coastal cities and towns to develop and design adaptation plans, the SDGs can serve several important functions. First, as the Sustainable Development Goals are reported at the national level, cities and towns that align adaptation plans with the SDGs can integrate their work into national climate change strategies, with a better chance at accessing national resources to do so. Likewise, small coastal cities and towns that have integrated the SDGs into their planning may have an easier time accessing international development resources, including knowledge and best practices as well as financial resources. A number of tools have been developed to assist cities and towns in the process of "localizing" the SDGs to specific contexts and assessing the impacts of different actions on achievement of the SDGs, such as the United Nations Development Programme's (n.d.) Climate Action Impact Tool (htt ps://climateimpact.undp.org) and United Nations Development Programme et al. (n.d.), online compendium of tools and resources for localization, "Localizing the SDGs" (http://localizingthesdgs.org).

\section{Declaration of competing interest}

The authors declare that they have no known competing financial interests or personal relationships that could have appeared to influence the work reported in this paper.

\section{Acknowledgements}

The corresponding author gratefully acknowledges support from Aalborg University for the work reported in this article. Co-authors acknowledge general support from their institutions for their contributions to the article.

\section{Appendix A. Supplementary data}

Supplementary data to this article can be found online at https://doi. org/10.1016/j.ocecoaman.2021.105789.

\section{References}

Baldacchino, Godfrey (Ed.), 2018. The Routledge International Handbook of Island Studies. Routledge: Taylor \& Francis Group, London and New York. 
Darwin, Charles, 1872. The Origin of Species. available digitally at:, sixth ed. on title page: "Reprinted from the. https://ia800504.us.archive.org/0/items/originofspecies b1899darw/originofspeciesb1899darw.pdf.

Depraetere, Christian, Dahl, Arthur, 2018. Locations and classifications,. In: Godfrey, Baldacchino (Ed.), The Routledge International Handbook of Island Studies, 2018. Routledge: Taylor \& Francis Group, London and New York (Chapter 2).

Island Studies Journal (ISJ). https://www.islandstudies.ca/.

Lehmann, M., Major, D.C., Fitton, J.M., Doust, K., O’Donoghue, S., 2021. Introduction to the Special Issue on Coastal Adaptation in Coastal Towns and Small Cities. Ocean and Coastal Management this issue.

MacArthur, Robert H., Wilson, Edward O., 1967. The Theory of Island Biogeography. Princeton University Press.

Major, David C., O'Grady, M., 2010. Adaptation assessment guidebook,. In: Rosenzweig, C., Solecki, W. (Eds.), New York City Panel on Climate Change, Climate change Adaptation in New York City: Building a Risk Management Response, Annals of the New York Academy of Sciences, New York Academy of Sciences. New York, Appendix B.

Major, David C., Lehmann, Martin, Fitton, James, 2018. Linking the management of climate change adaptation in small coastal towns and cities to the Sustainable Development Goals. Ocean Coast Manag. 163, 205-208.

Major, David, Juhola, Sirkku, 2016. Guidance for climate change adaptation in small coastal towns and cities: a new challenge. DOI: Journal of Urban Planning and Development 142 (4), 02516001-1-02516001-3. https://doi.org/10.1061/(ASCE) UP.1943-5444.0000356.

Major, David C., Juhola, Sirkku, 2021. Climate Change Adaptation in Coastal Cities, A Guidebook for Citizens, Public Officials and Planners. Helsinki University Press.
New York City, Office of the Mayor, 2013. PlaNYC: Progress Report 2013: AStronger, More Resilient New York. New York.

Neumann, B., Vafeidis, A.T., Zimmermann, J., Nicholls, R.J., 2015. Correction: future coastal population growth and exposure to sea-level rise and coastal flooding - a global assessment. PLoS One 10, e0131375. https://doi.org/10.1371/journal. pone. 0131375 .

Smit, B., Pilifosova, O., 2001. Adaptation to climate change in the context of sustainable development and equity. In: Climate Change 2001: Impacts, Adaptation, and Vulnerability-Contribution of the Working Group II to the Third Assessment Report of the Intergovernmental Panel on Climate Change. Cambridge University Press, Cambridge, pp. 877-912 (Chapter 18) of the Third Assessment Report of the IPCC.

United Nations, 2015. Transforming Our World: the 2030 Agenda for Sustainable Development. https://sustainabledevelopment.un.org/sdgs.

United Nations, 2016. Report of the Inter-Agency and Expert Group on Sustainable Development Goal Indicators (E/CN.3/2017/2), Annex III, Revised list of global Sustainable Development Goal indicators.

United Nations, n.d. Global SDG indicators database. https://unstats.un.org/sdgs/indi cators/database/. (Accessed 14 February 2019).

United Nations Development Programme, n.d. Climate action impact tool: assessing climate action contributions to the Sustainable Development Goals. https://climateimpact.undp.org/\#!/toolbar/main. (Accessed 14 February 2019).

United Nations Development Programme. UN habitat, and global task force of local and regional governments, n.d., toolbox for localizing the sustainable development goals. http://localizingthesdgs.org/. (Accessed 14 February 2019).

Vitousek, S., Barnard, P.L., Fletcher, C.H., Frazer, N., Erikson, L., Storlazzi, C.D., 2017. Doubling of coastal flooding frequency within decades due to sea-level rise. Sci. Rep. 7, 1399. https://doi.org/10.1038/s41598-017-01362-7. 